\title{
Hydro-mechanical behaviour of sandy silt under generalised stress conditions
}

\author{
Enrique Romero ${ }^{1 a}$, Octavio E. Cárdenas ${ }^{2}$, Antonio Lloret ${ }^{1}$ and Rodrigo C. Weber ${ }^{1}$

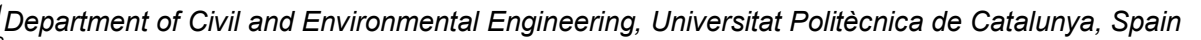

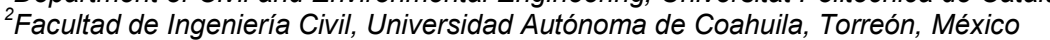

\begin{abstract}
This paper presents results on the deformation response of an artificially prepared sand-silt mixture in a hollow cylinder apparatus. The wetting stage was performed under constant mean net stress $\left(p^{\prime \prime}=200 \mathrm{kPa}\right)$ and deviatoric stress $(q=200 \mathrm{kPa})$ but at different intermediate principal stresses (controlled through the principal stress parameter $b=\left(\sigma_{2}-\sigma_{3}\right) /\left(\sigma_{1}-\sigma_{3}\right)$ and with values $b=0,0.5$ and 0.8$)$. Shear strength tests were first performed at constant mean net stress, different Lode angles and water contents (as-compacted and saturated) to ensure that the aforementioned stress state could be applied at the as-compacted water content. Consistent shear strength results were obtained when compared to triaxial compression and extension results at different water contents, which allowed defining the variation of the critical state line with Lode angle and suction. The soaking results indicated that collapse under constant mean and deviatoric stresses was larger when the intermediate stress coincided with the minor one, i.e. under conventional axi-symetric triaxial compression state $(b=0)$. This is a consequence of the dominant shear strains that occurred during saturation when the stress point reached the critical state line at $b=0.5$ and 0.8 .
\end{abstract}

\section{Introduction}

There are relatively few experimental results on the influence of the intermediate principal stress on the deformation response of unsaturated soils. Hoyos [1] and [2] used a true triaxial apparatus, whereas [3, 4] a hollow cylinder device, to perform tests under constant suction to study the influence of this constitutive stress variable on soil behaviour under generalised stress conditions.

Nevertheless and to the author's knowledge, the effect of intermediate stress and the rotation of principal stresses while suction is varying -particularly on the deformation response on soaking- have not been experimentally studied in depth. Suction changes may occur on compacted earthwork constructions and slopes, in which these effects (principal stress direction and intermediate principal stress) have been widely recognised (see for instance, [4-6]).

The authors of the present paper consider that this limitation is related to experimental difficulties, manly associated with the homogenisation of the hydraulic field (this is particularly important when working with a large sample as in the hollow cylinder apparatus and when liquid contact/pressure is applied at the lower boundary) and to the large deformations undergone on soaking. Deformation non-uniformities occur on soaking in the specimen as a result of its curvature and end-restraint effects, and this is important when selecting the type of transducers and the way to measure the displacement field and thus precisely determine the volume change response.

To get further experimental insight into the behaviour of unsaturated soils under generalised stress conditions, an experimental program has been launched to explore the deformation response of a lightly compacted and artificially prepared soil mixture during soaking at constant mean net stress $\left(p^{\prime \prime}=200 \mathrm{kPa}\right)$ and deviatoric stress $(q=200 \mathrm{kPa})$ and at different intermediate principal stresses. A mixture of $30 \%$ sand and $70 \%$ clayey silt by dry mass has been statically compacted at low dry density and low water content to induce high collapsibility on suction reduction. Shear strength tests in the hollow cylinder were also performed at constant mean net stress, different Lode angles and water contents (as-compacted and saturated) to define the position of the critical state line with Lode angle and suction, as well as to ensure that the aforementioned stress state could be applied under the as-compacted water content.

\section{Artificially prepared soil used in the investigation}

The soil used in the research was a mixture of two materials: fine sand of Castelldefels (Barcelona) and Barcelona $(\mathrm{BCN})$ clayey silt $[7,8]$. The particle size of the sand varied between $150 \mu \mathrm{m}$ and $1.18 \mathrm{~mm}$, with a density of solids of $2.65 \mathrm{Mg} / \mathrm{m}^{3}$. The clayey silt presented

a Corresponding author: enrique.romero-morales@upc.edu 
a liquid limit $w_{L}=36 \%$, a plastic index $P I=19 \%$ and a density of solids of $2.67 \mathrm{Mg} / \mathrm{m}^{3}$.

The mixing ratio was studied to find a suitable combination of shear strength, water permeability -given the large size of the sample-, measurable matric suction with tensiometer, and high collapsibility on soaking. Finally, a mixture of $30 \%$ sand and $70 \%$ clayey silt by dry mass was selected. The mixture with a water content of $4.0 \%$ (suction around $10 \mathrm{MPa}$ ) was statically compacted to a dry density of $1.55 \mathrm{Mg} / \mathrm{m}^{3}$ (void ratio $e=0.716$, degree of saturation $S_{r}=0.15$ ). The vertical stress applied to compact the sample was below $200 \mathrm{kPa}$.

Since the sand grains are immersed in the dominant clayey/silt matrix, it is important to know the real void ratio of the clayey silt. This real void ratio is $e_{c}=1.02$ (dry density $1.32 \mathrm{Mg} / \mathrm{m}^{3}$ ), which is large enough to induce an important collapse on wetting, to present a relatively high water permeability $k=5.85 \times 10^{-7} \mathrm{~m} / \mathrm{s}$ and to display suction values that are measurable by high-range tensiometer readings (at least for water contents above $8 \%[8])$.

A preliminary laboratory program was carried out with oedometer, direct shear cell and triaxial apparatus to explore the stress level associated with the maximum collapse zone (around a vertical stress of $200 \mathrm{kPa}$ ), pre and post-yield compressibility, and the shear strength properties. The water retention properties of the mixture on wetting were determined with psychrometer and highrange tensiometer readings. The water retention curves reported by [8] were used to estimate matric suction changes during the soaking process.

\section{Hollow cylinder apparatus}

The compacted sample was installed in the hollow cylinder apparatus (HCA) and featured $50 \mathrm{~mm}$ in external radius $r_{o}, 30 \mathrm{~mm}$ in inner radius $r_{i}$, and $200 \mathrm{~mm}$ in height $H_{o}$ (Figure 1). The capacity of the axial load cell and the torque cell were $10 \mathrm{kN}$ and $100 \mathrm{Nm}$, respectively. The principal stress parameter $b=\left(\sigma_{2}-\sigma_{3}\right) /\left(\sigma_{1}-\sigma_{3}\right)$ [9] was automatically controlled during the tests $\left(\sigma_{i}\right.$ are principal stresses, being $\sigma_{1}, \sigma_{2}$ and $\sigma_{3}$ the major, intermediate and minor ones, respectively). Both the base and top caps presented conventional porous discs. Three pressure/volume controllers were used for the application and control of the inner and outer cell pressures $\left(P_{0}\right.$ and $P_{i}$ in Figure 1), as well as for the measurement of the soil water volume changes. Figure 1 shows a scheme of the sample geometry, axial force $W$, torque $T$ and inner/outer pressures applied, as well as the stress state of the soil with the definition of the deviatoric stress $q$, mean stress $p$ and Lode angle $\theta$ invariants. The procedure to obtain the principal stresses from the applied force and pressures has been described in [10].

The axial strain $\varepsilon_{z}$ was evaluated directly from the vertical displacements controlled by the stepper motor and the initial height of the sample. The determination of volumetric $\varepsilon_{p}$, radial $\varepsilon_{r}$, and circumferential $\varepsilon_{\theta}$ strains needed the knowledge of the magnitude of the changes in the internal and external radii $w_{i}$ and $w_{o}$, respectively, indicated in the figure (see for instance, [10]). Due to the lack of local instrumentation and the relatively high volumetric deformation (volumetric strain on soaking was around $10 \%$ ), it was necessary to obtain these deformations from alternative recorded values. The changes in internal and external radii were evaluated from inner and outer chamber volume changes, which were measured by automatic pressure/volume controllers, together with height changes that were registered with stepper motor counts [8]. Outer chamber volume changes were corrected to take into account the deformability of the cell with pressure changes. The measurement of the final water content under saturated conditions, as well as the initial and final dry densities of the sample, allowed better assessing void ratio changes and volumetric deformation determination.

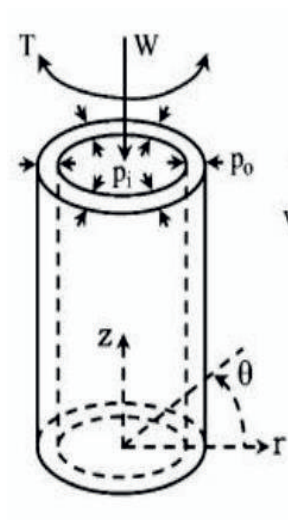

(b)
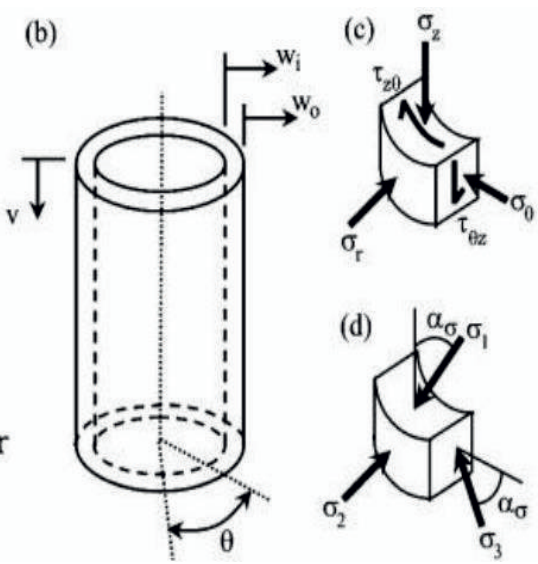

$$
\begin{aligned}
& \mathrm{q}=\frac{1}{\sqrt{2}} \sqrt{\left(\sigma_{1}-\sigma_{2}\right)^{2}+\left(\sigma_{2}-\sigma_{3}\right)^{2}+\left(\sigma_{1}-\sigma_{3}\right)^{2}} \\
& \mathrm{p}=\frac{\left(\sigma_{1}+\sigma_{2}+\sigma_{3}\right)}{3} \\
& \theta=\tan ^{-1} \frac{2 b-1}{\sqrt{3}} \\
& \sigma_{\mathrm{z}}=\frac{\mathrm{W}}{\pi\left(\mathrm{r}_{\mathrm{o}}^{2}-\mathrm{r}_{\mathrm{i}}^{2}\right)}+\frac{\mathrm{P}_{\mathrm{o}} \mathrm{r}_{\mathrm{o}}^{2}-\mathrm{P}_{\mathrm{i}} \mathrm{r}_{\mathrm{i}}^{2}}{\mathrm{r}_{\mathrm{o}}^{2}-\mathrm{r}_{\mathrm{i}}^{2}} \\
& \sigma_{\mathrm{r}}=\frac{\mathrm{P}_{\mathrm{o}} \mathrm{r}_{\mathrm{o}}+\mathrm{P}_{\mathrm{i}} \mathrm{r}_{\mathrm{i}}}{\mathrm{r}_{\mathrm{o}}+\mathrm{r}_{\mathrm{i}}} \\
& \sigma_{\theta}=\frac{\mathrm{P}_{\mathrm{o}} \mathrm{r}_{\mathrm{o}}-\mathrm{P}_{\mathrm{i}} \mathrm{r}_{\mathrm{i}}}{\mathrm{r}_{\mathrm{o}}-\mathrm{r}_{\mathrm{i}}} \\
& \tau_{\theta \mathrm{z}}=\frac{3 \mathrm{~T}}{2 \pi\left(\mathrm{r}_{\mathrm{o}}^{3}-\mathrm{r}_{\mathrm{i}}^{3}\right)}
\end{aligned}
$$

Figure 1. Sample geometry and stress state in the HCA.

\section{Shear strength results. Influence of intermediate principal stress}

Drained shear strength tests in the HCA were performed at constant mean net stress $\left(p^{\prime \prime}=200 \mathrm{kPa}\right)$, different Lode angles $\left(\theta=-30^{\circ}, 0^{\circ}, 19.1^{\circ}\right.$ and $30^{\circ}$, corresponding to $b=0$, $0.5,0.8$ and 1 , respectively), as well as different water contents (full saturation and as-compacted state). Drained shear strength tests were also complemented in the 
triaxial cell (compression tests TXC at $\theta=-30^{\circ}$ and extension tests TXE at $\theta=30^{\circ}$ ).

Figure 2 shows the evolution of the normalised shear strength results with Lode angle. The normalised shear strength at ultimate failure conditions (equivalent to the slope of the critical state line $M$ ) is expressed as $q_{f} /\left(p^{\prime \prime}+\mathrm{c}^{\prime} / \tan \phi^{\prime}\right)$, in which $c^{\prime}$ is the cohesion (that is affected by suction) and $\phi^{\prime}$ the drained friction angle (that is considered not affected by suction). As observed, consistent results were obtained when compared to TXC and TXE results at different water contents, which allowed defining the variation of the slope of the critical state line $M(\theta)$ with Lode angle and the variation of $c^{\prime}(s)$ with suction. The variation of $M(\theta)$ with Lode angle has been fitted to the following expression [11],in which $M_{e}=6 \sin \phi^{\prime} /\left(3+\sin \phi^{\prime}\right)$ and $M_{c}=6 \sin \phi^{\prime} /\left(3-\sin \phi^{\prime}\right)$

$$
\begin{aligned}
& M(\theta)=\frac{2 \mu}{(1+\mu)-(1-\mu) \cos 3\left(\theta+30^{\circ}\right)} M_{c} \\
& \mu=\frac{M_{e}}{M_{c}}=0.724 ; M_{c}=1.14
\end{aligned}
$$

Fitting test results allowed obtaining $\phi^{\prime}=28.7^{\circ}$ (the same for saturated and partially saturated states), a drained cohesion $c^{\prime}(0)=0$ under saturated condition and $c^{\prime}(s)=36 \mathrm{kPa}$ at $s=10 \mathrm{MPa}$. Direct shear tests on ascompacted and saturated states also reported similar results $\phi^{\prime}=29.7^{\circ}$ (not affected by suction), $c^{\prime}(0)=0$ under saturated condition and $c^{\prime}(s)=31 \mathrm{kPa}$ at as-compacted state.

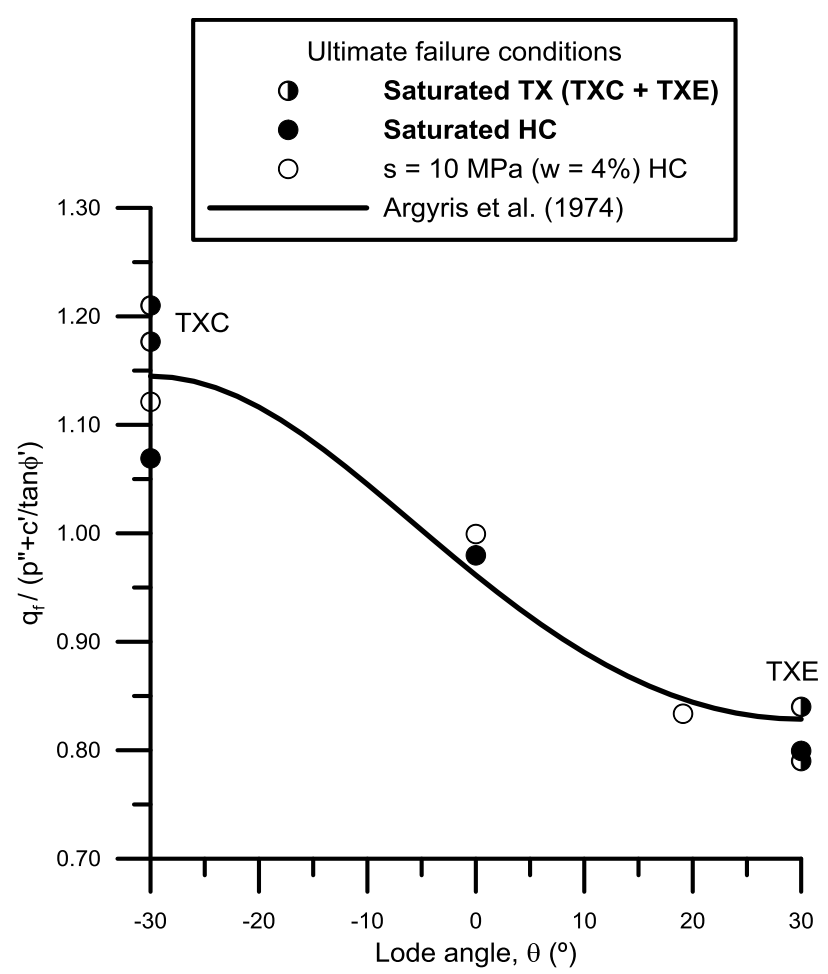

Figure 2. Shear strength results (influence of intermediate principal stress).

\section{Collapse at constant mean and deviatoric stresses. Influence of intermediate principal stress}

To determinate the effect of the intermediate principal stress $\sigma_{2}$ on collapse, three tests were performed by changing the value of parameter $b$, which was set to 0 , 0.5 and $0.8\left(\theta=-30^{\circ}, 0^{\circ}\right.$ and $19.1^{\circ}$, respectively $)$. The tests were carried out by maintaining constant the mean net stress $p^{\prime \prime}=200 \mathrm{kPa}$ and deviatoric stress $q=200 \mathrm{kPa}$ during the saturation stage. The test started with an isotropic compression stage by applying approximately the same inner and outer chamber pressures up to a maximum mean net stress $p^{\prime \prime}=200 \mathrm{kPa}$ at constant water content $(w=4.0 \%)$ and atmospheric pressure of air in soil. A rate of $2.5 \mathrm{kPa} /$ hour was selected for the application of the external $P_{o}$ and internal $P_{i}$ pressures during isotropic compression. After this initial stage, a small increase of deviatoric stress $q=30 \mathrm{kPa}$ was applied before setting parameter $b$.

Afterwards, the value of $q$ was increased at a rate of $15 \mathrm{kPa}$ /hour up to approximately $200 \mathrm{kPa}$ by maintaining $p^{\prime \prime} \approx 200 \mathrm{kPa}$ and approximately constant $b$ parameter. The shearing stages were carried out at $w=4.0 \%$. The paths in terms of principal strains $\varepsilon_{1}, \varepsilon_{2}$ and $\varepsilon_{3}$ followed during the deviatoric stress increase are shown in Figure 3. It should be remarked that values of $\varepsilon_{2}$ changed from negative (expansion) for the case of $b=0$, to positive (compression) for $b=0.8$. This behaviour was equivalent to the one observed in tests performed using a true triaxial equipment [1].
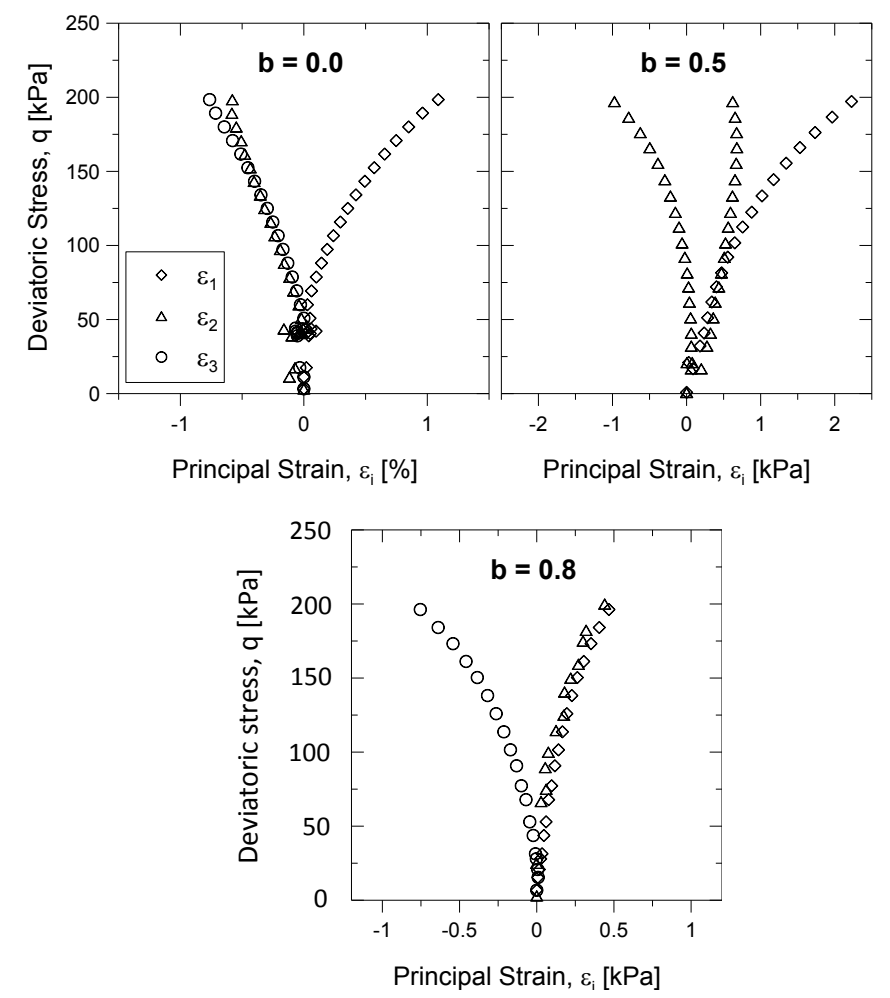

Figure 3. Evolutions of principal strains during deviatoric stress increase at constant $p^{\prime \prime}=200 \mathrm{kPa}$ and $w=4.0 \%$ for different values of $b$. 
Once the target stress state was reached, the samples were soaked under constant stress state by setting a small water pressure at the base (around $10 \mathrm{kPa}$ ). Water volume changes on soaking were monitored by an automatic pressure/volume controller. Table 1 presents the principal stresses and stress invariants at different $b$ values, which were kept constant along the wetting process. Figure 4 shows the measured and simulated evolutions of the global degree of saturation during the soaking process at constant $b=0$. The simulated evolution has been performed using a 1D infiltration model. Based on this model and considering the sample as a 'point test', the evolution of the (average) matric suction has been estimated by the water retention curve reported in [8]. The time evolution of this (average) matric suction has been also plotted in the figure.

Table 1. Principal stresses and stress invariants applied during the three soaking tests.

\begin{tabular}{ccccccc}
\hline $\boldsymbol{b}(-)$ & $\begin{array}{c}\sigma_{1} \\
(\mathbf{k P a})\end{array}$ & $\begin{array}{c}\boldsymbol{\sigma}_{2} \\
(\mathbf{k P a})\end{array}$ & $\begin{array}{c}\boldsymbol{\sigma}_{3} \\
(\mathbf{k P a})\end{array}$ & $\begin{array}{c}\boldsymbol{q} \\
(\mathbf{k P a})\end{array}$ & $\begin{array}{c}\boldsymbol{p} \\
(\mathbf{k P a})\end{array}$ & $\begin{array}{c}\boldsymbol{\theta} \\
\left({ }^{(}\right)\end{array}$ \\
\hline 0 & 340 & 125 & 125 & 215 & 197 & -30 \\
0.5 & 320 & 205 & 90 & 200 & 205 & 0 \\
0.8 & 290 & 245 & 60 & 211 & 198 & 19.1 \\
\hline
\end{tabular}

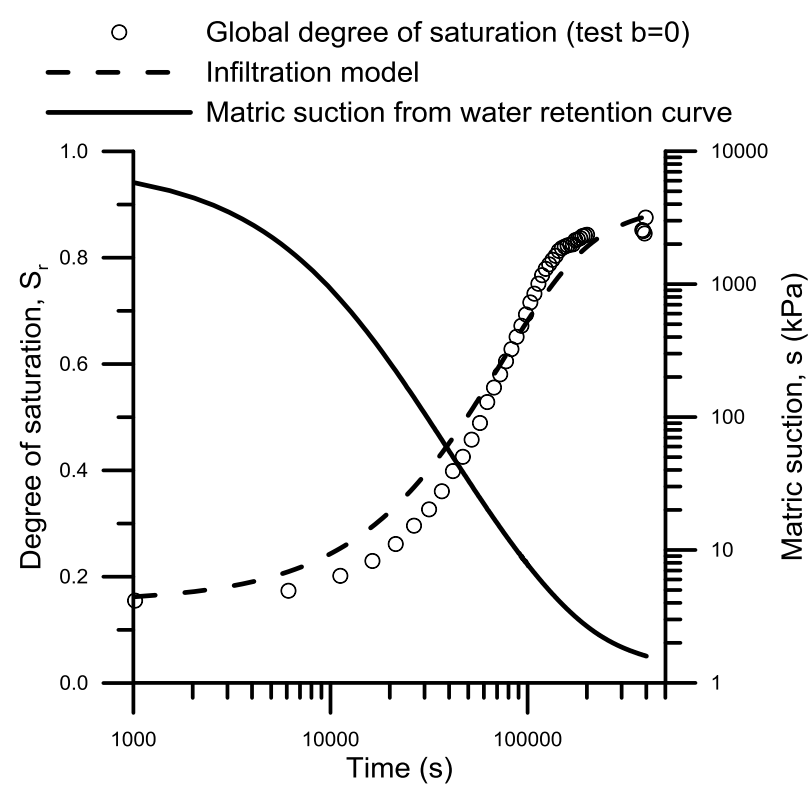

Figure 4. Time evolution of the global degree of saturation of the sample along the soaking process (test at $b=0$ ). Time evolution of average matric suction (sample considered as a 'point test').

Figure 5 shows the time evolution of the volumetric strain $\varepsilon_{p}$ (associated with collapse) for different values of $b$ during the saturation stage at constant $p^{\prime \prime} \approx 200 \mathrm{kPa}$ and $q \approx 200 \mathrm{kPa}$. Important collapse strains were recorded along the three soaking tests. Final $\varepsilon_{p}$ values around $20 \%$, $9.6 \%$ and $8.4 \%$ were measured at the end of these soaking stages for values of $b=0, b=0.5$ and $b=0.8$, respectively. These results seemed to indicate that collapse under constant mean and deviatoric stresses was larger when the intermediate stress coincided with the minor one, i.e. under conventional axi-symetric triaxial compression state.

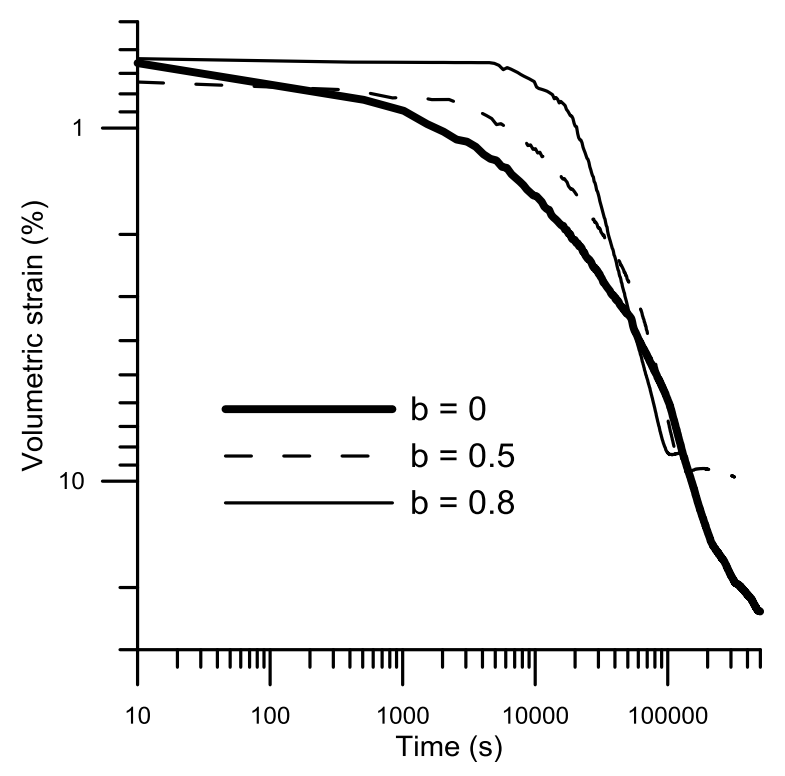

Figure 5. Time evolutions of volumetric strains (collapse) during soaking at different $b$.

The stress state ( $p^{\prime \prime}=200 \mathrm{kPa}$ and $q=200 \mathrm{kPa}$ ), which is kept constant during the soaking process, is plotted in Figure 6 for different $b$ values. The position of the initial (as-compacted) critical state line, together with the initial cap yield surface, is also indicated in the figure (thick solid lines). This cap yield surface has been plotted according to Barcelona Basic Model (BBM) [12]. As observed, the stress state at a normally consolidated condition lies on the yield surface of the cap. The distance between the stress point and the initial (ascompacted) critical state line reduces as parameter $b$ increases (this is a consequence of the reduction of the slope $M(\theta)$ as the Lode angle increases).

During soaking, the slope of the obliquity of the stress point $q /\left(p^{\prime \prime}+c^{\prime} / \tan \phi^{\prime}\right)$ (dashed lines in Figure 6 at the top) increases due to the reduction in $c^{\prime}$, which is affected by suction decrease. As a first approximation, a linear variation of $c^{\prime}(s)$ with suction has been considered between $c^{\prime}(0)=0$ at $s=0$ and $c^{\prime}(s)=36 \mathrm{kPa}$ at $s^{\prime}=10 \mathrm{MPa}$. In addition, the position of the critical state lines is shifted towards a reduction in the elastic domain during suction reduction (thin solid lines with the same slope $M(\theta)$ as the initial ones). In fact, the final position of the critical state line reaches the stress point in the case of $b=0.5$ and 0.8 during saturation. In neither of these cases, $c^{\prime}$ does not reach a value of 0 . This means that the deformational response on soaking is dominated by shear strains $\varepsilon_{q}$ in 


\section{E-UNSAT 2016}

the case of $b=0.5$ and 0.8 (besides the occurrence of collapse deformations). This can be better appreciated in the direction of the plastic flow vectors depicted in the figures and plotted according to BBM [12] (vectors plotted in thick lines represent the initial conditions before the soaking takes place, whereas vectors in thin lines are associated with the final saturated condition).
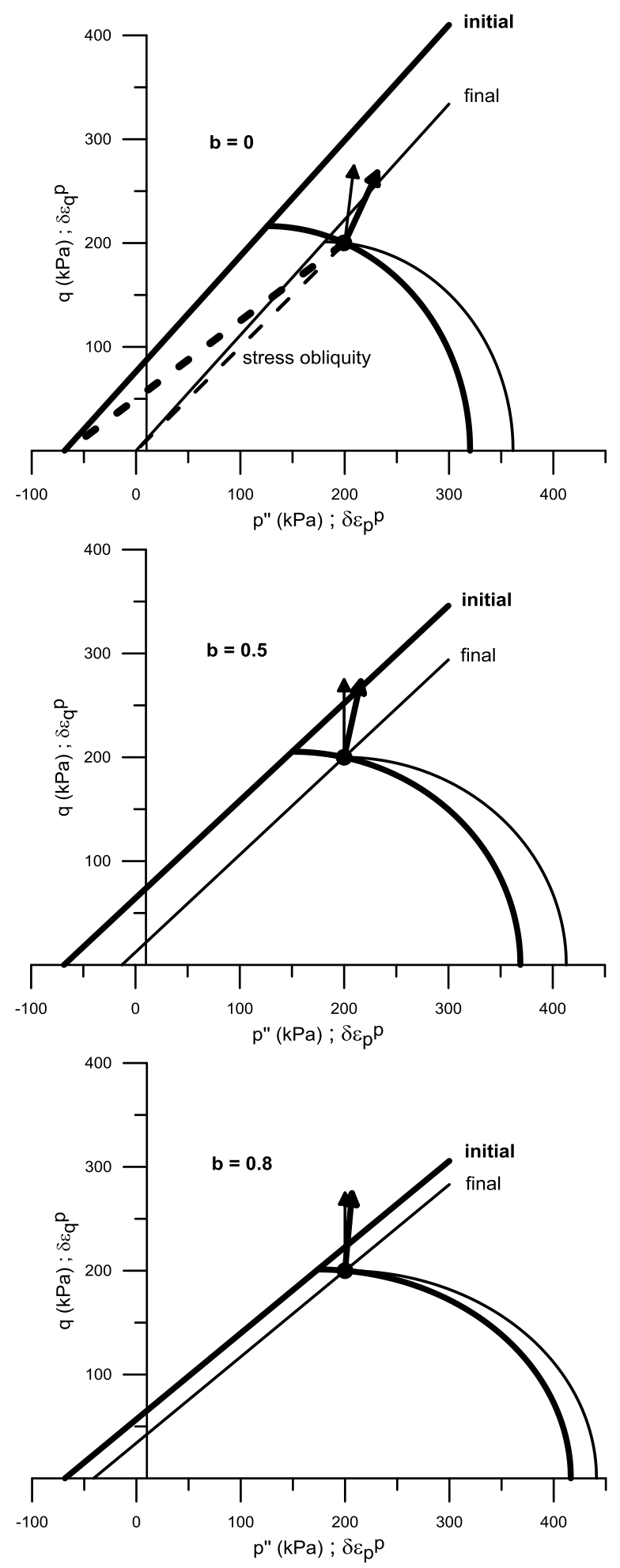

Figure 6. Stress state during soaking. Initial and final cap yield loci and critical state lines. Initial and final plastic flow vectors.
Figure 7 shows the evolution of the inclination of the plastic vectors (measured and modelled through BBM [12]) along the soaking process. As observed, the inclination of the plastic vectors stabilises at $b=0$, which is not the case of $b=0.5$ with dominant plastic shear strains. A relatively good agreement between measured and modelled responses can be observed.

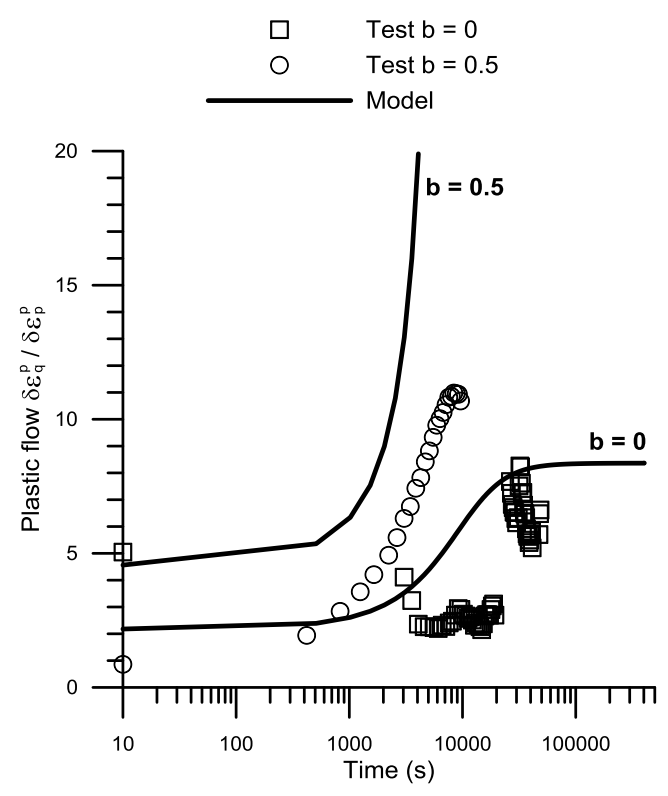

Figure 7. Time evolutions of the inclination of plastic vectors for different $b$ values. Experimental data and model results.

The experimental normalised volumetric strains (with respect to the maximum value at $b=0$ ) are presented in Figure 8 for different Lode angles. The figure also includes model predictions. As observed, BBM predicts a reduction consistent with measured values at increasing Lode angles.

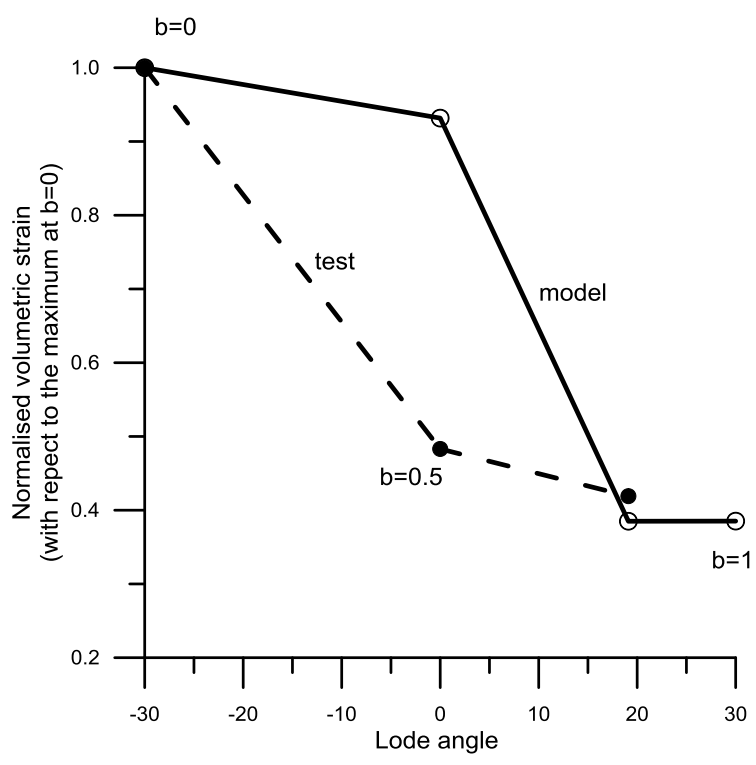

Figure 8. Evolution of normalised volumetric strain during soaking (with respect to the maximum value at $b=0$ ) for different Lode angles. Experimental data and model results. 


\section{Summary and concluding remarks}

A mixture of $30 \%$ sand and $70 \%$ clayey silt by dry mass was statically compacted at low dry density $\left(1.55 \mathrm{Mg} / \mathrm{m}^{3}\right)$ and low water content $(4.0 \%)$ to induce high collapsibility on suction reduction. A preliminary laboratory program was carried out under oedometer conditions to explore the stress level associated with the maximum collapse zone of the mixture (around a vertical stress of $200 \mathrm{kPa}$ ). With this information, a laboratory test program was started aimed at studying the influence of intermediate principal stress on the deformation response of the mixture at an equivalent mean stress to that of the maximum collapse under oedometer conditions. A conventional HCA was a suitable equipment to perform these tests, provided that changes in inner and outer diameters of the specimen were correctly evaluated from volume changes of inner and outer chambers and by taking into account the initial and final dry densities of the material. The HCA was also used to explore the changes of the slope of the critical state line with Lode angle, as well as the variation of cohesion at different water contents (as-compacted and saturated).

Deformation results on soaking at constant mean and deviatoric stress $\left(p^{\prime \prime}=200 \mathrm{kPa}\right.$ and $q=200 \mathrm{kPa}$ ) showed to be influenced by the intermediate principal stress. Test results indicated that collapse was larger when the intermediate principal stress was equal to the minor one ( $b=0$ and Lode angle $\theta=-30^{\circ}$ ), as in conventional axisymmetric triaxial compression conditions. A systematic decrease of collapse strain was detected as the intermediate principal stress tended to the major principal one (increasing $b$ or Lode angle).

Test results were interpreted by considering the slope of the obliquity of the stress point $q /\left(p^{\prime \prime}+c^{\prime} / \tan \phi^{\prime}\right)$, which increased due to the reduction in $c^{\prime}$ (affected by suction decrease). In addition, the position of the critical state line was shifted towards a reduction in the elastic domain during suction reduction. At $b=0.5$ and 0.8 , the critical state line reached the stress point inducing a deformational response governed by dominant shear strains (besides collapse deformation) during the saturation episode.

\section{Acknowledgements}

The fourth author acknowledges the financial support of Capes Scholarship Proc. Bex13299/13-1 (Brazil).

\section{References}

1. L.R. Hoyos, Georgia Institute of Technology PhD Thesis, (1988)

2. H. Matsuoka, D.A. Sun, A. Kogane, N. Fukuzawa, W. Ichihara, Can. Geotech. J. 39, 608-619, (2002)

3. H. Toyota, N. Sakai, T. Nishimura, Soils and Foundations 41, 1 13-24 (2001)

4. H. Toyota, K. Nakamura, W. Sramoon, Soils and Foundations 44, 5 1-13 (2004)

5. F.Z. Zerfa, B. Loret, Soil Dynamics and Earthquake Engineering 23, 435-454 (2003)

6. L. Zdravkovic, D.M. Potts, D.W. Hight, Géotechnique 52, 6 447-457 (2002)

7. E. Romero, Engineering Geology 165, 3-19 (2013)

8. O. E. Cárdenas, R. C. Weber, E. Romero, A. Lloret, J. Suriol, Proc. $6^{\text {th }}$ Int. Symposium on Deformation Characteristics of Geomaterials, IOS Press Amsterdam, 462-469 (2015)

9. A.W. Bishop, Géotechnique 16, 2 91-128 (1966)

10. D.W. Hight, A. Gens, M.J. Symes, Géotechnique 33, 4 355-383 (1983)

11. J.H. Argyris, G. Faust, J. Szimmat, E.P. Warnke, K.J William, Nuclear Engrg. and Design 8, 42-75 (1974)

12. E.E. Alonso, A. Gens, A. Josa, Géotechnique 40, 3 405-430 (1990) 